\title{
Almôndegas tolstoístas
}

\section{Dmitri Bykov}

Nota biográfica: Dmitri Lvóvitch Bykov nasceu em Moscou, em 1967, formando-se em jornalismo na Universidade Estatal de Moscou Lomonóssov em 1991, após ter interrompido o curso por dois anos, enquanto servia o exército. Exerceu a profissão nos principais periódicos russos, tais como "Ogoniók", de importância fundamental na época da glasnost, e "Sobessiednik" para a qual colabora até hoje como crítico literário. Apesar de se considerar essencialmente jornalista, Bykov é também escritor, poeta, professor, radialista e apresentador de televisão, para a qual criou o projeto Grajdanin Poet em parceria com o ator Mikhail Efremov. Sendo um dos mais prolíferos autores russos da contemporaneidade, Bykov ganhou o prêmio Bestseller Nacional e Bolshaia Kniga pela biografia de Boris Pasternak, em 2006. Além desta, escreveu também as biografias de Maksim Górki e do músico soviético Bulat Okudjava. Como romancista, publicou oito livros em cerca de dez anos. Sua obra é ainda mais vasta ao somarmos os contos, ensaios, poesias.

Almôndegas tolstoístas foi publicado em 2007, na coletânea "JD rasskazi”, iniciada sob encomenda para a revista "Sokvoiage SV", de circulação gratuita para os passageiros das linhas férreas russas. A temática da coletânea é o topos recorrente da literatura russa, a via férrea, o qual é incorporado por Bykov não só no enredo, mas também na estrutura de seus contos. O conto aqui traduzido é o primeiro do projeto que visa divulgar o trabalho de Bykov em língua portuguesa.

$$
* * *
$$

Kórobov $^{1}$ pela janela da cabine via perfeitamente que no pescoço do antipático companheiro de viagem pendurava-se uma moça magra, de cabelos pretos, muito séria, de uns vinte e dois anos. Via que ela passava voando pela plataforma para, nos últimos cinco minutos, conseguir dizer algumas palavras de despedida. Via também que ela

\footnotetext{
${ }^{1}$ Nikolai Serguéevitch Kórobov, nascido em 1985 em Novosibirsk, um dos principais escritores contemporâneos de ficção científica na Rússia. [N.T.]
} 
tinha olhos desesperados, olhos de mulher apaixonada que sozinha não entende o que acontece consigo, e se assusta com essa mudança repentina. Kórobov conhecia esse tipo de boas meninas de família que se comoviam com um grande amor - muitas vezes por alguém completamente insignificante - e destruíam seu mundo confortável em uma semana. Às vezes se tornavam mulheres fatais extraordinárias, mas isso só dois ou três casos em cem. Já as outras quebravam-se para sempre. A menina era admirável, e nisto é que estava a questão. Ele, por hábito, reparou na mão direita dela e encontrou uma aliança. Não tirara, portanto. E o companheiro não tinha aliança. Pensando bem, isso ainda não queria dizer nada.

A antipatia do companheiro não se encerrava no desleixo com que saudara Kórobov, nem no cuidado com que pendurara a capa de chuva; nem no modo como, ao sair à plataforma para fumar e esperar sua linda mulher, levara consigo sua pasta, aparentemente com medo de deixá-la sozinha com Kórobov; também não estava na forma como alisava os cabelos diante do espelho, enfim lançando um olhar exigente para si $\square \square$ será que estou suficientemente bem penteado e firme para me despedir da mulher amada? Mas ainda ensaiaremos essa expressão especial um pouco enjoada que os machos fortes da minha classe fazem diante de qualquer demonstração de sentimento... A antipatia estava na presunção geral, sutil, no resquício do linguajar chulo de que personagens almofadinhas assim nunca podem se livrar, apesar de todas as aulas de boas maneiras, paletós decentes e dos melhores parfums. A principal virtude dos arruaceiros $\square$ a inabalável atitude de levar-se muito a sério $\square$ podia ser sentida em tudo, apesar de Kórobov ter observado seu futuro companheiro só por três minutos. O bacana entrou, acenou com desleixo, pendurou a capa de chuva, sentou-se à mesa e, em silêncio, pegou a pasta e saiu para fumar na plataforma, aonde logo veio ao seu encontro a morena. Eis aí todo o material para observações. Mas somos gente experiente, macacos velhos, então isso é o que nos basta. Também, a escolha deste trem expresso nos diz algo. Não estamos indo de "Krásnaia Strelá", ${ }^{2}$ o máximo do sonho soviético e exemplo do luxo vermelho, mas de "Liev Nikoláievitch", estilizado como aquele que interrompeu o sofrimento de Anna Kariênina. Somente um idiota pôde nomear um trem de "Liev Nikoláievitch", pois todas as principais desventuras da vida

\footnotetext{
${ }^{2}$ Em russo "seta vermelha". Trem de alta velocidade que circulou entre São Petersburgo e Moscou a partir de 1931. Primeira marca da União Soviética, usada posteriormente em diversos filmes, canções e na literatura para referir-se a tal momento histórico. [N.T.]
} 
do nosso conde Nikoláitch ${ }^{3}$ foram consequências da estrada de ferro: nele se arruinou a heroína favorita, por ele pôs-se a viajar o idiota Pózdnichev de "Sonata a Kreutzer", por ele fugiu de casa e nele morreu. No "Nikoláitch" tinha muitas outras coisas de mau gosto: um retrato do conde na locomotiva, como na melhor tradição de trens agit ${ }^{4}$ almôndegas "tolstoístas" de carne bovina (embora todos saibam que a partir dos sessenta anos o conde foi um vegetariano inveterado); cabineiros de gibões com a risca do cabelo oleosa, uma combinação natural de ignorância, luxo e amor ufanista ao patrimônio nacional. Só metidos e estúpidos que não lamentam gastar trezentos bucks por um bilhete até Píter ${ }^{5}$ escolhem esse expresso. Tudo bem, eu... eu não estou aqui por vontade própria, assim decidiram os organizadores, enquanto ele...

Despediram-se, ela se acalmou, cansou de tanto chorar. Com um longo e suplicante olhar, contemplava o rosto liso e quadrado, sem falar nada. Meu Deus! - pensou Kórobov -, como eu sou invejoso! Talvez pensem que nunca ninguém se despediu assim de mim; mas houve muitas despedidas, só que nunca terminaram bem. Ele acariciava o cabelo dela com uma imponência condescendente, olhando por cima de sua cabeça - provavelmente para sua brilhante perspectiva financeira... Já está claro que diante de nós havia um pequeno empresário que estava indo para Píter fechar uns negócios. Agora você vai ver só esta viagem, meu filho...

O companheiro entrou, o vagãozinho se moveu, a morena conseguiu bater à janela (Kórobov previsivelmente se virou, embora ela não pudesse ver nada de lá de fora...), o destruidor de corações acenou para com desleixo, ajeitou-se à mesinha e, por fim se dignou a estender a mão e se apresentar:

- Serguei.

— Nikolai - mentiu Kórobov, não se sabe por quê.

— Nada mal esse trenzinho, não? Podem, quando querem.

Agora ele dirá que os negócios estão melhorando, que não é mais uma vergonha morar neste país. É um leal businessman da nova geração. Não falou; fez o papel de nobre discreto, ainda que fosse evidente que estava explodindo de felicidade. Ele queria

\footnotetext{
${ }^{3}$ Diminutivo carinhoso de Nikoláievitch. [N.T.]

${ }^{4}$ Abreviação de Agitação e Propaganda, agitprop é a ideologia de disseminação do comunismo entre a sociedade por meio da mobilização das massas, palavras de ordem e até mesmo pela politização das artes. [N.T.]

${ }^{5}$ Maneira coloquial de se referir a São Petersburgo. [N.T.]
} 
conversar. Tinha acabado de receber outra confirmação da vida de como era brilhante ser o maioral, veja só! Veja as moças que correm para se despedir de nós, com que olhar suplicante nos veem apesar de irmos embora provavelmente por três dias... Como ficarão ali esses três dias, sem nós, sem os quais o céu sobre Moscou chora? ... ${ }^{6}$

— Esposa? - perguntou Kórobov acenando para a janela.

- Amiga. - Serguei desfez-se em um sorriso. Então Kórobov soube que chegou ao assunto.

Era justamente sobre isso que o companheiro desejava conversar em um tom leve, condescendente, descuidado. De modo geral, quem entende esse eterno gosto dos apaixonados por contar sobre sua felicidade? Nós nos questionamos por que surgiu tanta publicidade na imprensa e na telinha, mas não tem nada a ver com grana, só os materialistas bobos conseguem explicar tudo por ela. A explicação está na felicidade: é preciso compartilhá-la. Eis que aqui temos as cuecas embranquecidas e limpas, os dentes embranquecidos, as pernas longas e o expresso "Nikoláitch"! Nós colocamos nosso anúncio em todo lugar não porque queremos atrair seu coração, dentes e outros órgãos para nossos produtos... não... estamos compartilhando a felicidade, o prazer de possuir... senão explodiríamos de alegria!

— Que gata, hein? - perguntou Serguei de repente com um sorriso estúpido. E debaixo da máscara quadrada de homem bem-sucedido surgiu a cara de moleque simples que teve sorte.

Kórobov concordou com vigor e fez um gesto de positivo.

— Está sofrendo - disse Serguei.

— Passará muito tempo em Píter?

- Hum, uma semana no máximo. Mas estamos acostumados, todo dia... Eu mesmo fico um pouco nervoso.

— Tudo bem, por causa de uma semaninha...

— Lá está o marido. - disse Serguei, sério.

Kórobov ficou alerta.

\footnotetext{
${ }^{6}$ Referência ao filme soviético Moscou não acredita em lágrimas (1980). [N.T.]
} 
— Você quer dizer o marido dela? Como assim? Ele sabe?

— Desconfia. Ele a torturou completamente. Um otário!

— Bom, mas qual é o problema disso? Ela ainda é jovem, tipo, a época não é mais a tolstoiana. Para que se fazer de "Anna Kariênina"? É só partir, conversar, explicar, levála...

- Ela não quer - disse Serguei, triste. Percebia-se que ele mesmo se surpreendia com essa situação: ele é tão maravilhoso e ela não quer. Enquanto isso outras fazem fila, lambendo seus pés.

— O quê? Tem um filho?

— Um filho seria bom, eu ficaria com o filho. Tudo está indo de mal a pior. Ela é muito honesta.

Aham, aham. Conhecemos esse tipo. Vamos para cama? $\square$ Então sim, por favor. Vamos deixar essa situação mais clara? $\square$ Então é honesta.

— E então, não quer se separar?

— Aham. Diz que ele não aguentará.

- Sabe, - confidenciou Kórobov. - Posso chama-lo de "você"? Sabe, nós sempre exageramos a respeito da incapacidade do outro de sobreviver sem nós. Sei por experiência própria quantas vezes caí nessa.

- Sim, foi o que eu falei para ela! - disse Serguei entusiasmado. Aparentemente era com essa entonação que convencia os parceiros de business, e se esse jeito não ajudava, recorria às ameaças diretas. - Falei: por acaso ele é criança? Qual é o problema? Eu mesmo entendo que se ali houvesse algo... mas ele é um zero à esquerda, um fracassado! É um inútil! Você viu como está vestida? Sabe como eu a vestiria?

Kórobov não só vira. Sabia como ela estava vestida, isso é uma outra questão. No geral, já sabia muito sobre ela.

- Mas assim não posso nem comprar nada pra ela! Ele vai ver e na hora vai perguntar: de onde veio a grana? Ela é roteirista de um talk show, sozinha não tem de onde tirar. Já ele é um tal... tem algo nas relações públicas... por outro lado, escreve. Ninguém 
publica, mas ele escreve. É escritor. Quando ela se atrasa, ele grita, saliva... Não entendo de jeito nenhum que tipo de homem é esse.

— Alguns são assim... - concordou Kórobov com conhecimento de causa, incentivando a franqueza do companheiro.

— E ela fala que não é como todos. Especial, né? Ela fala que, se for embora, ele perde os parafusos.

— O que tinha na cabeça quando se casou com ele? - interessou-se Kórobov.

- Ah, não tinha nada, estava no quarto ano da faculdade... Pensava no que pensam todas elas...

- Hm, pode ser que na cama tenha algo especial? Sabe, existe esse apego e, por causa disso... - Kórobov piscou o olho e tirou uma garrafa de Hennessy da sacola.

- Ali na cama... - Serguei sorriu. - Eu sei um pouquinho do que acontece ali na cama e... nisso eu de algum jeito ganharia. Não, ele me dá pena. Só faz escândalos para ela. Ora grita, ora jura: dois dias sem você e eu me enforco...

— Mas pelo menos não bate nela, não?

— O quê? Bater? Se alguma vez ele batesse nela, eu o seguiria e o quebraria todo.

— E ela não quer apresentar você?

— Que pergunta! Ela chora na hora. No geral é séria, com ela não se pode facilitar. No começo eu pensava: ah, bom, então só de vez em quando, mas depois nós dois caímos nessa. Que pergunta! Não é dessas que costuma... Sou seu terceiro, percebe? Vinte e três anos e sou o terceiro, né?

De fato, em uma conversa com o companheiro de viagem nós somos mais sinceros do que em um confessionário.

Vindo do telefone de Serguei, o toque insistente da moda chamou a atenção. Ele olhou por um momento para o número conhecido e ficou sério.

- Sim, sim, bebê. - Para Kórobov foi difícil não sorrir triunfante, pois sabia, sabia direitinho quem era o "bebê". Variantes: pequena, docinho. É possível "gatinha". Sim, normal. Eu também, bebê. Não, eu ligo assim que chegar. Sim, sim. Escute, bebê, o que é uma semana? São três dias e depois três, e no quarto já estou aí. Sim. Não, não 
se atreva. Não precisa. E o que você vai falar pra ele? Hum, não... Hum, pode ser que eu consiga me livrar antes. Tá bom, beijinhos.

— O quê? Quer te encontrar? - sorriu Kórobov de propósito.

— Sim, disse que vai conseguir se livrar... mas onde vou ficar lá com ela? Eu estou indo a negócios.

— Vai uma aí? Kórobov mostrou o rótulo.

— Vamos lá, teríamos que bater um rango.

—É só apertar o botão e eles trazem direto para cabine. Eu não quero me acotovelar até o restaurante, lá está a gentalha, a escória...

Com a frase sobre a gentalha Kórobov pensava em comprá-lo de uma vez por todas - e não estava enganado. As pessoas do tipo do Serioja ${ }^{7}$ obrigatoriamente devem se sentir mais refinadas que seus similares. Sobre isso eles todos escrevem seus Dukhless: ${ }^{8}$ nós somos finos e temos sentimentos, mas à nossa volta todos são uma gentalha que arranja treta, engabela, cagueta e cheira carreiras. É claro que não queremos nos acotovelar no meio dessa gentalha e temos preguiça de atravessar três vagões. Nós agora vamos pedir na cabine, e um garçom-bajulador concebido para satisfazer nossas altas necessidades vai logo nos trazer, em travessas com tampa de vidro cheias de vapor dentro, duas porções de almôndegas "tolstoístas" com a couve-flor predileta do conde e molho bechamel.

Acompanhado pelo conhaque e pelas almôndegas "tolstoístas", na realidade trazidas depois de uns dez minutos, Kórobov ficou sabendo de mais coisas, embora "ficar sabendo" não seja exatamente a palavra. Ele recebeu uma confirmação, porque sabia de tudo. O marido era mais velho que nossa heroína, e até então já tinha conseguido se divorciar, tornar-se mesquinho, exigente, invejoso, odiar os ricos e insultar o poder com xingamentos chulos. Torturava a mulher com perguntas e críticas. No primeiro ano forçou-a a viver com sua mãe, uma velha louca, professora aposentada que, apesar de

\footnotetext{
${ }^{7}$ Diminutivo de Serguei. Diminutivos são uma forma de tratamento familiar, amigável, carinhosa ou, em alguns casos, irônica, depreciativa, muito comum entre os russos. [N. T.]

${ }^{8}$ Romance de Serguei Minaev escrito em 2006. O livro narra a vida de um gerente de 30 anos, o qual acredita indubitavelmente em seu sucesso e felicidade. Sua vida se resume às festas, gastar dinheiro e usar drogas, até que conhece uma moça diferente e começa a mudar sua perspectiva de vida. Em 2012 foi adaptado para o cinema pelo diretor Roman Prygunov. Em russo, o título significa "o sem sentimentos", "o desumano", o "desalmado". Foi traduzido para o inglês como Soulless. [N.T]
} 
tudo, continua ensinando a todos até hoje. Era admirável quanta sujeira sua "bebê" conseguia contar sobre o marido. Parece que este era um tema frequente em suas conversas. A "bebê" rapidamente soube que Serioja gostava de escutar a desgraça alheia, e de todo jeito tentava agradá-lo. Serioja se sentia bem só se estivessem babacas ao seu redor. Kórobov rápido e discretamente deu a entender que agora ele mesmo estava com um problema - os peterburguenses não aprovam o projeto de reconstrução da região Petrográdskaia, todos os pedidos são distribuídos de acordo com seu desejo, mas ele é uma visita moscovita, arquiteto convidado... Serguei concordou com a cabeça, complacente: - Ah, sim, Píter é uma província, não sabe voar! Ele mesmo produzia sucos, sim. Espremia o suco do proletariado moscovita e empacotava em caixinhas de papelão. Top manager do Bim-bim-don, ${ }^{9}$ ouviu? Como não ouvir, se diariamente passamos por um monstrinho pseudo-marmorizado na Miasnítskaia, com um Bim-bimdon de plástico entre um bando de crianças também de plástico, em frente à entrada principal. Sim, os sucos são todos diluídos. Desiludir quem amamos, isso não podemos, mas os sucos - isso é fácil.

As almôndegas não estavam nada mal. É bom ser dono da vida. Serioja quis impressionar e pagou a conta. Pois bem, comemos por conta do Bim-bim-don. Mas demos-lhe ainda mais conhaque. Sua língua desatou rapidamente e vieram os detalhes, que eram um pouco fantasiosos. É improvável que essa menina seja capaz de tais coisas, como sexo oral à noite no parque, é improvável que Serioja seja capaz de causar-lhe tais sentimentos, de modo que uma criatura decente e de família deseje algo tão quente exatamente na Tvierskáia ${ }^{10}$ - mas poderia ele embebedá-la?

- Não, o que está dizendo. Acontece que antes ela não via nada disso. Tudo pela primeira vez. Fico pensando: como eu a levaria a Bali! Como eu mostraria Veneza pra ela! Mas como vou mostrar Veneza? Ela não consegue se livrar pra Píter sequer por um dia. Ela tem medo de tudo, tem medo que ele a siga.

— Mas como seguiria? Será que contratou alguém?

— Eu também falo para ela: onde ele arranjou grana? Ele não tem bala na agulha para contratar alguém! E ela diz: não, eu sinto. Ele já a assombra. Às vezes eu digo pra ela:

\footnotetext{
${ }^{9}$ Referência à indústria de laticínios Wimm-Bill-Dann, uma das maiores da Europa, que desde 2010 pertence ao grupo Pepsi\&co. Produz iogurte, leite, sucos e também refrigerantes. [N. T.]

${ }^{10}$ Uma das principais ruas de Moscou, localiza-se na região central da cidade e é, desde o século XVIII uma das mais movimentadas, representando o centro da vida social moscovita. [N.T.]
} 
olhe ali, o Pétia! ${ }^{11}$ E ela se contorce toda. Mas eu nunca vi os olhos de Pétia, nem sei como é o tal Pétia. E a foto ela não mostra - desatou a rir Serioja.

— Tá, o que tem lá para ver - concordou Kórobov com a cabeça. - Imagino que seja feio. Os copywriters são todos feios.

— Pois é! - exclamou Serioja, endossando o desprezo senhoril pela poeira de escritório.

— Está bem, Séri ${ }^{12}$ - disse Kórobov, servindo a última dose - A você, à sua sorte, a sua bebê, e que todos que nos incomodam morram o mais rápido possível!

Serioja bateu o copo fino "tolstoiano" com tanto entusiasmo no copo de Kórobov que até derrubou algumas gotas na toalha engomada que cobria a mesa. Ele bebeu conhaque como vodka - de um só gole, sem sentir o gosto, sem elogios, sem ritual, enfim, sem tudo aquilo que dá à vida seu encanto. Essas pessoas tragam a vida, engolem-na, devoram os pedaços sem se importar com o gosto ou com o cheiro; assim eles usam nossas mulheres, incapazes de notar as pintas em seus ombros e as veias no colo, não se lembram do cheiro de seus cabelos, não entendem a cor e a expressão de seus olhos. E que morram todos aqueles que nos incomodam!

— Esticaremos as canelas juntos! - disse Kórobov.

Serioja concordou mecanicamente, mas não teve tempo de se embriagar por completo e então ficou alerta.

— Em que sentido? - perguntou ele.

— Literal, - acenou Kórobov, confirmando. - você entendeu tudo certo, queridinho. Em uns quarenta minutos, uma hora.

No rosto de Serioja refletiu-se um doloroso trabalho mental. Ele empalideceu, já que estava muito vermelho. Apesar de ser setembro, no "Nikoláitch" o sistema de aquecimento era de inverno.

— Então não lespila? - perguntou Kórobov com a frase de sua anedota preferida. Mas como lespilava, como lespilava! ${ }^{13}$ Não queria ver Pétia, queridinho? Então veja,

\footnotetext{
${ }^{11}$ Diminutivo de Piotr. [N.T.]

${ }^{12}$ Diminutivo de Serioja. [N.T.]

${ }^{13}$ Referência à anedota popular em que uma criança, flagra a mãe e o amante na cama, e, após o pai chegar em casa e o amante se esconder no armário, pergunta ao amante: “agora não lespila? Mas como
} 
afinal! Pétia, é claro, é muito babaca e não está nos negócios. Mas vocês não são conspiradores, meu amigo. Ou você pensou que eu e o Bim-Bim-Don não tínhamos nossa gente? Você também não se escondeu bem.

Serioja sacou o celular. Esse era o seu gesto preferido, a solução de todos os problemas.

- Qual o ponto? - perguntou Kórobov, olhando para ele fixamente. - Seria melhor você sentar e ouvir. Talvez eu possa lhe dizer algo útil afinal...

— Ah é? - perguntou Serioja com uma voz pesada. Era visível que para ele já era difícil respirar, e ele até assobiou levemente.

- Vamos supor que você ligue para seus caras em Píter. E vamos supor que lá nos encontrem seus caras, mesmo se eu não conseguir descer em Bologóie, ${ }^{14}$ o que você não pode prever. E o que essa gente fará comigo? Ali, depois de uma hora vão ter dois cadáveres, meu queridinho. Pra que merda eu vou viver depois de tudo isso? Você pensa o quê, não viu - pois eu também bebi. Tudo foi honesto.

Serioja se enrijeceu e parecia não entender a língua humana. Kórobov estalou os dedos na frente do seu nariz.

- Acalme-se, acalme-se, Séri. Concentre-se. Em uns dez minutos você vai apagar, é preciso apressar-se. Eu quero que você entenda. Não pretendo matar você sozinho, sacou? Nós dois ali deitaremos, irmãos de leite. Você sabe o que é irmão de leite? Essa expressão é para quando os dois transam com uma só. Eu estou cansado das mentiras dela, entende? Na minha vida, além dela, eu não tinha nada. E se ela é assim, como ela é, e se pôde ficar com um como você... isso significa o fim do mundo, me entende, Serioja? Por isso eu não vou viver, Serioja. Não quero cobrir pegadas, desviar, correr, tremer ao som da campainha. Entendeu? Mas suponha que eu morra e que você fique vivo. Com isso também não posso, Serioja. Não posso deixar o mundo e deixar você como dono dele. Por isso estou aqui, Serioja. Eu não preciso ir a Píter, lá não tenho nem onde ficar.

Serioja entendia aos poucos. Ele com certeza já prestara atenção a si mesmo e percebera como o frio subia lentamente pelas pernas.

lespilava, como lespilava”. Em russo, дысис é uma corruptela de дышишь, que denota a fala de uma criança. [N.T.]

${ }^{14}$ Cidade russa na região de Tver. [N.T.] 
Bateram à porta da cabine.

— Não vai fazer besteira, Serioja. - advertiu Kórobov. - Sim, pode entrar!

- Os senhores desejam sobremesa? - perguntou o garçom, sorrindo. Nas tavernas esse empregado chamava-se serviçal. - O melhor que temos é a sexual sonata a Kreutzer. Também temos o blancmange "Depois do baile"...

— Será que é com sangue? - perguntou Kórobov.

- Com o quê, senhor? - perguntou o garçom.

— E a sobremesa "Ressurreição" vocês não têm?

— Não, senhor. - respondeu o serviçal, pesaroso. - Ainda não inventaram, senhor.

— Tá bom, - acenou Kórobov. - Não existe nenhuma ressurreição. Vai, querido, eu chamo você se precisar. Tome aqui um "Falso cupom".

Agradecido, o serviçal aceitou a gorjeta. A porta se fechou suavemente.

- Mas eu não tomei nenhum antídoto, Serioja, $\square$ disse Kórobov, antecipando o palpite ingênuo do companheiro. - Porque não tem antídoto. Você ouviu sobre batracotoxina? É mais forte que Curare, você está pensando o quê. Extrai-se da pele da rã colombiana de Chocó. E não é nenhum problema conseguir em Moscou. Há um especialista na feira de animais.

— Mas aí você viajou - de repente disse Serioja tranquilo.

— Como assim? - alarmou-se Kórobov.

- A feira de animais foi demolida. Agora lá fica o Zoocentro Kalítnikovski. É preciso conhecer Moscou, Konstantin Nikoláievitch, isso é o que eu diria pro senhor.

Kórobov ficou calado por um tempo.

- Não, eu entendo tudo, claro, $\square$ disse Serioja, acendendo um cigarro. - Você se incomoda se eu fumar? Somos só nós dois na cabine, depois ventilamos... Eu entendo tudo: Píter, todos os negócios. Não somos dignos de conhecer a realidade moscovita. Mas se você já resolveu desempenhar essa simulação, é preciso de alguma forma, eu não sei, estar pronto, ou algo assim. E depois, sabe qual é a principal viagem dos peterburguenses? A arrogância imperdoável. Assim que os seus começaram a vir até 
nós, eu logo notei. Eles até pensam que nós somos todos uns burros. Não lemos "Labirintos de estrelas", não ouvimos falar de "A morte verde", nem conhecemos "Guardiões do vale"... 15

Kórobov sentiu-se lisonjeado. Ele não imaginou que managers do Bim-Bim-Don o leriam.

- Eu logo saquei - sorriu Serioja. - Mas, achei que pedir um autógrafo seria chato. Imagino que esses autógrafos te atormentem. Você foi participar do "O caminhante", não é?

"O caminhante", em homenagem à famosa trilogia de Lukiáchkin, foi o nome dado ao Congresso Anual de Ficção Científica nos arredores de Moscou, na qual Kórobov recebeu dos fãs a garrafa de Hennessy. Ele mesmo geralmente não comprava essas bebidas caras.

— De "O caminhante"... - disse, mexendo a cabeça.

- Neste ano não consegui ir - disse Serioja desapontado. Mas na verdade sou um fã dos antigos. Se não fosse você, eu não teria conseguido nada na vida. O que é essencial para um top manager? O principal para ele é deixar a fantasia voar. Você é mestre nisso!

— Puxa, então você... é um leitor assíduo - disse Kórobov entediado.

— Ahá! - Serguiei não sentiu a ironia. - Hum, sabia que você faria alguma esquisitice. Pronto. Quando você se apresentou como Kólia, eu entendi tudo. Oh, acho que agora começamos a jogar! Nada poderia ser melhor do que ganhar esse autógrafo!

— A bebê, claro, esposa... - acenou com a cabeça o escritor de ficção.

— Não, - disse Serioja triste - Sobre a bebê é tudo verdade. Se fosse para inventar, eu inventaria para fazer rir.

- Triste.

- Que tristeza que nada... E eu entrei bem no seu jogo, certo? Coloque isso em algum conto!

\footnotetext{
${ }^{15}$ Referência a Serguei Lukiánenko. Nascido em 1968, no Casaquistão, é um dos escritores de ficção científica e fantasia mais populares da Rússia atualmente. [N.T.]
} 
- Colocarei. - disse Kórobov.

— E agora vamos beber normalmente, - disse Serioja, pegando uma garrafa de Martel.

Ele apertou um botão e chamou o garçom. - Escute, moço: traga-nos mais daquelas... "tolstoianas". E o que você tem aí de entradas frias?

— Salada "Felicidade conjugal". - sorriu o garçom.

— Bem, traga. - decidiu Serioja - Pelo menos dá para vê-la como salada...

Tradução: Eloah Pina Pereira ${ }^{16}$

\footnotetext{
${ }^{16}$ Formada em Letras (FFLCH), atualmente é mestranda em Cultura e Literatura russa pela Universidade
} de São Paulo e assistente editorial na Cosac Naify. Endereço eletrônico: eloah.pina@gmail.com 